NJE Vol. 36: 88-95, 2020

Nigerian Journal of Entomology

Published by the Entomological Soc. of Nig.

www.esnjournal.com.ng

DOI.10.36108/NJE/0202/63.01.01

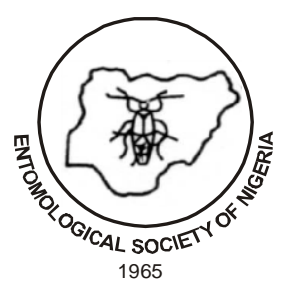

\title{
Effect of Temperatures on the Pathogenicity of Entomopathogenic Nematodes (Steinernema carpocapsae and Heterorhabditis bacteriophora) for Biocontrol of Octodonta nipae (Maulik)
}

\author{
Sanda, N. B., ${ }^{1,2,3}$ Wudil, B. S. ${ }^{3}$ and Hou, Y.M. ${ }^{1,2 *}$ \\ ${ }^{1}$ State Key Laboratory of Ecological Pest Control for Fujian and Taiwan Crops \\ Fujian Agriculture and Forestry University, Fuzhou, Fujian, China \\ ${ }^{2}$ Fujian Province Key Laboratory of Insect Ecology, Department of Plant Protection \\ Fujian Agriculture and Forestry University, Fuzhou, Fujian, China \\ ${ }^{3}$ Department of Crop Protection, Faculty of Agriculture, Bayero University, Kano, 3011 \\ BUK, Kano, Nigeria
}

\begin{abstract}
In the 21st century climate change has been recognized globally as the most impending, and critical issue that affects all animals including insects. In particular, temperature plays an important role in the development, reproduction, host searching, survival, pathogenicity, sex ratio and insect death. The Nipa palm hispid, Octodonta nipae (Maulik) is an important invasive pest of palm trees in Sothern China. Knowledge of how this beetle can be controlled with entomopathogenic nematodes under different environmental temperature is scarce. Therefore, the aims of this study were to test the efficacy of two entomopathogenic nematodes (Steinernema carpocapsae and Heterorhabditis bacteriophora) at different development temperatures. The pathogenicity was tested at concentration of $100 \mathrm{IJs}_{\text {larva }}{ }^{-1}$ and treatment are kept at four temperatures of $20,25,30$ and $36^{\circ} \mathrm{C}, 80 \pm 5 \% \mathrm{RH}$. The results showed that, both nematodes species caused larval mortalities at all the tested temperatures except at $36^{\circ} \mathrm{C}$. The highest larval mortalities of $85.3 \%$ and $40.6 \%$ were obtained at $30^{\circ} \mathrm{C}$ for both $S$. carpocapsae and $H$. bacteriophora respectively. Furthermore, both nematodes penetrated $O$. nipae larvae at all temperature conditions except at $36^{\circ} \mathrm{C}$. Similarly, the highest penetrations of nematodes infective juveniles were recorded at $30^{\circ} \mathrm{C}$ for $S$. carpocapsae and $H$. bacteriophora. The study demonstrated that, warmer temperature enhanced the pathogenicity of nematodes, which in turns trade well with the unprecedented increase in environmental temperature under climate change, for integrated management of this beetle.
\end{abstract}

Keywords: Biocontrol; Heterorhabditis bacteriophora; Octodonta nipae; Penetration; Steinernema carpocapsae; Temperature.

*Correspondence email:

ibrothe1983@gmail.com 


\section{INTRODUCTION}

Nipa palm hispid beetle, Octodonta nipae (Maulik) (Coleoptera Chrysomelidae: Cassidinae), is an important pest of palm trees, that causes great economic loss by attacking leaf fronds of host trees. This is done by adults and young larvae; which are the most destructive stages of this pest (Hou et al., 2014). These however resulted in shrinkage, curling, and in some situations death of the young leaves (Hou et al., 2010; Tang and Hou, 2017). O. nipae is native to Malaysia, and was first reported in 2001 in Hainan island, China (Sun et al., 2003) where it damaged California fan palm Washingtonia filifera (Linden ex André) $\mathrm{H}$. Wendl. The main control method of this pest is the use of insecticides, which are usually inefficient. Because both adults and larvae lives together within the tight central leaves of the palm, thus, escaped from the exposure of the insecticide (Vassiliou et al., 2011). However, Tetrastichus brontispae; an endoparasitoid of $O$. nipae was used for biocontrol of pupae (Howard et al., 2001). Entomopathogenic fungus Metarrhizium anisopliae has also been reported as biocontrol agent of this pest (Xin et al., 2009; Chen et al., 2010; Nguyen et al., 2012; $\mathrm{Xu}$ et al., 2012). As part of integrated pest management, the use of suitable, cost effective and environmentally friendly methods for this pest is required.

Entomopathogenic nematodes (EPNs) are biological control agents for different economically important agricultural pests from laboratory to field levels (Lacey et al., 2015). The most widely used EPNs are from the families' Steinernematidae and Heterorhabditidae, because of their ability to actively search for their hosts (Sanda et al., 2018), they are recently shown to be effective for the control for leaf feeding insects (Labaude and Griffin, 2018). The
EPNs are reported to be used for control of quarantine leaf eating caterpillars and other insect pests on many crops such as adult western corn rootworm Diabrotica virgifera LeConte (Lavine and Strand, 2002), flea beetles (Phyllotreta spp.) (Yan et al., 2013) and the Colorado potato beetle Leptinotarsa decemlineata found in leaf surfaces (Trdan et al., 2009).

Temperature is one of the abiotic factors that play important roles in affecting the infectivity, time of death, development, reproduction and storage of EPNs (Susurluk 2008). However, temperature tolerance of EPNs is different between species and strains (Koppenhöfer et al., 2000). Thus, EPNs isolates from specific regions have considerable variations in their abilities to infect the host, kill it and reproduce within it are all influenced by temperature characteristics of their original habitats (Mahar et al., 2007). However, information of how this insect interacts with entomopathogenic nematodes and surrounding temperature especially due to climate change is needed. Thus, the study therefore, evaluated the pathogenicity and penetrations of two EPN species, $S$. carpocapsae All (Weiser) and $H$. bacteriophora H06 (Poinar), against third instar larvae of $O$. nipae in the laboratory at different developmental temperatures.

\section{MATERIALS AND METHODS}

\section{Insects and Nematodes cultures}

Adults of $O$. nipae were collected and reared with small piece of fortunes windmill palm, Trachycarpus fortunei (Hook) in the laboratory as reported by Sanda, et al, (2018). The insects were maintained at $25 \pm$ $1^{\circ} \mathrm{C}, 80 \pm 5 \% \mathrm{RH}$, and photoperiod of 12: 12 (Light: Dark) (Sanda et al., 2019). $S$. carpocapsae All (Weiser) and $H$. bacteriophora H06 (Poinar) were obtained from Guangdong Institute of Applied 
Biological Resources, China. Nematodes were cultured using the last instar larvae of greater wax moth, Galleria mellonella. Infective juveniles (IJs) were stored in distilled water at $13^{\circ} \mathrm{C}$ and were used in all experiments within 15 days of emergence from the host.

\section{Effects of temperature on Mortality of $\boldsymbol{O}$. nipae larvae}

Bioassays were conducted to determine the pathogenicity of $S$. carpocapsae All (Weiser) and H. Bacteriophora H06 (Poinar) at 100 IJs larvae ${ }^{-1}$ concentration for the control of O. nipae larvae in 96-well plates (Costar®, Corning Incorporated Corning, New York 14831, USA) as described by Sanda et al (2018). Briefly, thirty larvae of $O$. nipae were placed individually in each well plate containing $1 \times 2 \mathrm{~cm}$ of tissue paper with small piece of fortunes windmill palm, T. fortune $i$ (Hook) $(35,1)$. IJs were diluted to $10 \mu \mathrm{l}$ at and applied to each well containing one larva. To prevent escape of the larvae, the micro titer plates were covered with the lid and kept at $20,25,30$ and $36^{\circ} \mathrm{C}, 80 \pm 5 \%$ RH, and a photoperiod of 12: 12 (Light: Dark) in incubators. For the control experiment, $10 \mu 1$ tap water was used. Larval mortality was recorded at 24 and 48 hours after treatments (HAT) and the experiments were run in triplicate to confirm the results.

\section{Effects of temperatures on IJs penetration}

Bioassays were prepared as described above, to assess the penetration of the EPNs into the host larvae. The treatments were transferred to incubators sets at $20,25,30$ and $36^{\circ} \mathrm{C}, 80$ $\pm 5 \% \mathrm{RH}$ after treating each well containing single larva with $10 \mu \mathrm{lJ}$ s suspension. After 72 hours, ten dead larvae (cadavers) were picked from the well plates, rinsed with distilled water and dissected under dissecting Stereomicroscope. The number of penetrated
IJs were counted and recorded. The experiments were run in triplicate to confirm the results.

\section{Statistical Analysis}

All statistical analyses were performed using IBM SPSS Statistics version 22 (IBM Corporation, New York, 10504-1722, United States) (SPSS, RRID: SCR_002865). Data were corrected for control mortality using Abbott formula (1925) and percentage data were square-root transformed to meet assumptions of normality and homogeneity of variances. The percentage corrected cumulative mortalities data, Penetration of EPN on $O$. nipae larvae data were analyzed by one way Analysis of variance (ANOVA). When ANOVA showed a significance effect $(\mathrm{P}<0.05)$, means were compared or separated using least significance differences (LSD) at $\alpha .5$.

\section{RESULTS}

\section{Effects of different temperatures on mortalities of $O$. nipae}

The results revealed that, both nematodes species caused larval mortalities at all the tested temperatures except at $36^{\circ} \mathrm{C}$ treatments throughout the experiments. Therefore, the results were excluded from data analysis at $36^{\circ} \mathrm{C}$. The results of the percentage cumulative mortality are presented in Figure 1 for $S$. carpocapsae and $H$. bacteriophora. There were significant differences among the three temperature conditions in mortality of third instar larvae caused by $S$. carpocapsae at $24 \mathrm{~h}\left(F_{2,6}=\right.$ 23.32, $P<0.001)$ and $48 \mathrm{~h}\left(F_{2,6}=39.27\right.$, $P<0.001)$ after treatment. Similarly, there were significant differences among the three temperature conditions in mortality of third instar larvae infected by $H$. bacteriophora at $24 \mathrm{~h}\left(F_{2,6}=21.13, P<0.001\right)$ and $48 \mathrm{~h}\left(F_{2,6}\right.$ $=29.96, P<0.001)$ after treatment. However, 
differences exist in the mortality of third instar larvae between the $S$. carpocapsae and $H$. bacteriophora treatments at both $24 \mathrm{~h}$ and $48 \mathrm{~h}$ after treatments. At $24 \mathrm{~h}$, the $S$. carpocapsae and $H$. bacteriophora treatments differs significantly when conditioned at $20{ }^{\circ} \mathrm{C}\left(t_{4}=14.86, P=0.001\right), 25{ }^{\circ} \mathrm{C}$ $\left(t_{4}=18.65, P=0.001\right)$ and $30{ }^{\circ} \mathrm{C}\left(t_{4}=37.26\right.$, $P=0.001)$ temperatures. In the same vein, the $S$. carpocapsae and $H$. bacteriophora treatments differs significantly at $20{ }^{\circ} \mathrm{C}\left(t_{4}=\right.$ 2.76, $P=0.001), 25^{\circ} \mathrm{C}\left(t_{4}=5.85, P=0.001\right)$ and $30{ }^{\circ} \mathrm{C}\left(t_{4}=16.36, P=0.005\right)$ temperatures conditions $48 \mathrm{~h}$ after treatments. At 24 hours after inoculation (Figure 1A) the highest mortalities of $85.3 \pm 6.9 \%$ were recorded at $30^{\circ} \mathrm{C}$ for the $S$. carpocapsae treatment. Similarly, in the H. bacteriophora, the percentage larval mortalities of $O$. nipae were less than that recorded for $S$. carpocapsae treatments at all-time points (Figure 1 B). However, the highest mortalities of $64.14 \pm 2.5 \%$ were recorded at $30^{\circ} \mathrm{C}$ followed by $25^{\circ} \mathrm{C}(47.01 \pm 1.8 \%)$ at $48 \mathrm{~h}$ after $H$. bacteriophora treatments.

\section{Effects of different temperatures on IJs penetration}

Temperatures had significant effects on the mean penetration of IJs for the $S$. carpocapsae $\left(F_{2,6}=2.215 ; P<0.008\right)$ and $H$. bacteriophora $\quad\left(F_{2,6}=16.7 ; \quad P<0.004\right) \quad$ as presented in Figure 2. However, significant differences exist between $S$. carpocapsae and $H$. bacteriophora IJs penetration at $20^{\circ} \mathrm{C}$ $\left(t_{4}=16.14, P=0.001\right), 25{ }^{\circ} \mathrm{C}\left(t_{4}=10.25\right.$, $P=0.001)$ and $30{ }^{\circ} \mathrm{C}\left(t_{4}=40.11, P=0.001\right)$. The highest mean penetrations rates of IJs of $79.67 \pm 3.70$ and $22.49 \pm 1.79 \mathrm{IJs} /$ larva were recorded at $30^{\circ} \mathrm{C}$ for $S$. carpocapsae and $H$. bacteriophora respectively.

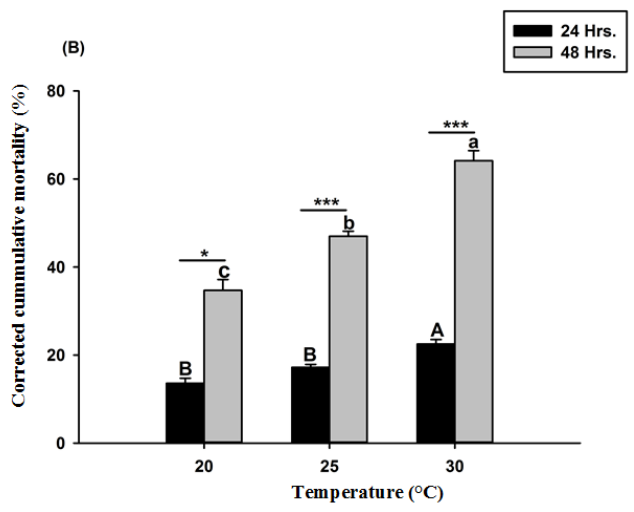

Figure 1: Cumulative mortality of third instars larvae of Octodonta nipae at different temperature of Steinernema carpocapsae and Heterorhabditis bacteriophora. Steinernema carpocapsae at 24 and 48 hours after treatment (B)Heterorhabditis bacteriophora at 24 and 48 hours after treatment. Means with the same letter above bars are not significantly different using Oneway ANOVA followed by least significance differences (LSD). Means shown by different letters are significantly different at $0.05 \%$

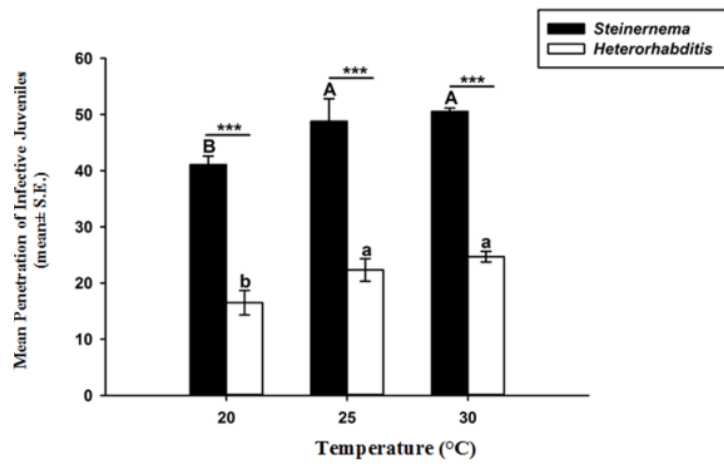

Figure 2: Mean penetration of infective juveniles of Steinernema carpocapsae and Heterorhabditis bacteriophora at different temperatures into third instars of Octodonta nipae. Means with the same letter above bars are not significantly different using One-way ANOVA followed by least significance differences (LSD). Means shown by different letters are significantly different at $0.05 \%$ 


\section{DISCUSSION}

The host pathogen interactions can be affected by temperature as reported in nematodes and other agents such as fungi, viruses, bacteria and parasitoid (Menti et al., 2000; Thomas and Blanford, 2003; Mahar et al., 2007). This can either be directly or indirectly by triggering host defense mechanism. The results of this study indicated that, applications of two EPNs of $S$. carpocapsae and $H$. bacteriophora for the control of $O$. nipae larvae resulted in the higher larval percentage mortalities at $30^{\circ} \mathrm{C}$. For Steinernematid species, different authors reported results with higher mortalities of insect hosts at higher temperatures. Lalramnghaki et al (2016) reported Steinernema spp caused $100 \%$ percentage insects mortalities at $30^{\circ} \mathrm{C}$. Similarly, $100 \%$ mortalities of $G$. mellonella and Agrotis ipsilon larvae caused by $S$. carpocapsae were reported by Bussaman et al., (2009) at temperature range of 25 and $32^{\circ} \mathrm{C}$. Maximum mortalities of Conogethes punctiferalis were reported for Steinernema spp and Heterorhabditis spp at $30^{\circ} \mathrm{C}$ (Miduturi et al., 1994).

Additionally, maximum percentage mortality of $86.7 \%$ and $80.0 \%$ for $S$. carpocapsae and Heterorhabditis spp respectively at $31^{\circ} \mathrm{C}$ were reported for Ceratitis capitata larvae. Grewal et al. (1993) reported higher efficiency of $S$. carpocapsae at higher temperatures of $30^{\circ} \mathrm{C}$ and above (Tarasco et al., 2015). This trend is unique to Steinernematids, as for most of the experiments using $H$. bacteriophora similar trends of higher percentage mortality were reported at higher temperatures Yadav (2016). It was speculated that, the higher mortalities of these EPNs might be traced to their origins, which is believed to be characterized by mild winter and hot summer regions (Shapiro-Ilan et al., 2012).This study also gains support from Mahar et al. (2007) reported higher mortalities of $P$. cochleariae larvae at $30^{\circ} \mathrm{C}$ by $H$. bacteriophora. Similarly, $98 \%$ G. mellonella larval mortality was highest by $H$. bacteriophora than other EPNs used in the experiment (Linder et al., 2008; Lee et al., 2016).

In our experiment IJs penetrations of $S$. carpocapsae and $H$. bacteriophora were also maximums at $30^{\circ} \mathrm{C}$ among the tested temperatures. Similarly according to Rashid, et al (2015), higher IJs penetrations into $C$. punctiferalis larvae were reported for Steinernema spp and Heterorhabditis spp at $30^{\circ} \mathrm{C}$ (Linder et al., 2008; Lee et al., 2016). In addition to these, Mahar, et al. (2007) reported higher penetrations of $H$. bacteriophora and $H$. indica at $30^{\circ} \mathrm{C}$ in Phaedon cochleariae and contrarily higher penetration of $S$. carpocapsae and S. feltiae at $25^{\circ} \mathrm{C}$. In similar host larvae, a UK stain of S. carpocapsae showed higher number of IJs during infectivity test at temperature range of $25-26^{\circ} \mathrm{C}$ (Rohde et al., 2010). Maximum infections of $S$. riobrave were observed at $28.5^{\circ} \mathrm{C}$ against Pectinophora gossypiella, this is more or less similar to our finding (Shapiro-Ilan et al., 2012). To sum it all, our result is in line with reports that, changes in temperature not only change the immune response of the insects, but also the degree of pathogen infectivity (Mahar et al., 2007).

\section{CONCLUSION}

Overall, in this study, our results revealed that, the warmer the temperature, the more the mortality of $O$. nipae larvae. Molecular and physiological data are also needed to find out why warmer temperature favoured infectivity of nematodes and makes $O$. nipae larvae susceptible at this condition. This study demonstrated the possibility of using EPNs against $O$. nipae in integrated 
management programs in combination with other control methods under field conditions.

\section{ACKNOWLEDGMENTS}

We thank Prof. Richou Han and his associate Dr. Xun Yun for providing us with Entomopathogenic nematodes for the experiment. This work was supported by grants from the National Natural Science Foundation of China (31471829) and the National Key R\&D Program of China (2017YFC1200600).

\section{REFERENCES}

Abbott, W. (1925). A method of computing the effectiveness of an insecticide. J. econ. Entomol, 18 (2), 265-267. DOI: 10.1093/ jee/18.2.265a

Bussaman, P., Sobanboa, S., Grewal, P.S. and A. Chandrapatya (2009). Pathogenicity of additional strains of Photorhabdus and Xenorhabdus (Enterobacteriaceae) to the mushroom mite Luciaphorus perniciosus (Acari: Pygmephoridae). Applied Entomology and Zoology, 44(2): 293-299.

Chen, S., J. Li, X. Han and M. Moens (2003). "Effect of temperature on the pathogenicity of entomopathogenic nematodes (Steinernema and Heterorhabditis spp.) to Delia radicum." BioControl, 48(6): 713-724.

Grewal, P.S., Gaugler, R., Kaya, H.K. and M. Wusaty (1993). Infectivity of the entomopathogenic nematode Steinernema scapterisci (Nematoda: Steinernematidae). J Invertebr Pathol, 62(1), 22-28. DOI: 10.1590/S1519-566X2001000200001.

Hou, Y. and Z. Weng (2010). Temperaturedependent development and life table parameters of Octodonta nipae (Coleoptera: Chrysomelidae). Environ Entomol, 39(5), 1676-1684.

Hou, Y., Miao, Y. and Z. Zhang (2014). Study on Life Parameters of the Invasive Species Octodonta nipae (Coleoptera: Chrysomelidae) on Different Palm Species, Under Laboratory Conditions. J Econ Entomol, 107(4), 1486-1495. DOI:10.1603/ec14119.
Howard, F.W., Moore, D., Giblin-Davis, R. and R. Abad (2001). Field techniques for studies of palm insects. Insects on Palms, 322.

Koppenhöfer, A.M., Grewal, P.S. and H.K. Kaya (2000). Synergism of imidacloprid and entomopathogenic nematodes against white grubs: the mechanism. Entomol Exp Appl, 94(3), 283-293.

Labaude, S. and C.T. Griffin (2018). Transmission success of entomopathogenic nematodes used in pest control. Insects, 9(2): 72.

Lacey, L.A., Grzywacz, D., Shapiro-Ilan, D.I., Frutos, R., Brownbridge, M. and M.S. Goettel, (2015). Insect pathogens as biological control agents: Back to the future. Journal of Invertebrate Pathology, 132: 1-41.

Lalramnghaki, H.C. (2016). "Effect of temperature on the infectivity of EPN." Science Vision Science Vision 16 (1) (January-March): 21-25.

Lavine, M.D. and M.R. Strand (2002). Insect hemocytes and their role in immunity. Insect Biochemistry and Molecular Biology, 32: 1295-1309.

Lee, J.H., Dillman, A.R. and E.A. Hallem (2016). Temperature-dependent changes in the host-seeking behaviors of parasitic nematodes. BMC Biol, 14(1), 36.

Linder, J.E., Owers, K.A. and D.E. Promislow (2008). The effects of temperature on hostpathogen interactions in D. melanogaster: Who benefits?. J Insect Physiol, 54(1), 297308.

Mahar. A.N. Jan, G. Mahar, M. Hullio, A. Lanjar and A. Buriro (2007). "Effectiveness of entomopathogenic nematodes against the larvae of mustard beetle Phaedon cochleariae at different temperatures." Int J Agr Biol, (Pakistan).

Menti, H., Wright, D.J. and R.N. Perry (2000). Infectivity of populations of the entomopathogenic nematodes Steinernema feltiae and Heterorhabditis megidis in relation to temperature, age and lipid content. Nematology, 2(5): 515-521. 
Miduturi, J.S., De Clercq, R., Casteels, H. and A. De Grisse (1994). Effect of temperature on the infectivity of entomopathogenic nematodes against black vine weevil (Otiorhynchus sulcatus F.). Parasitica, 50: (3-4) 103-108.

Nguyen, H., Oo, T., Ichiki, R., Takano, S., Murata, M., Takasu, K.K., K.S. Tunkumthong and S. Nakamura (2012). Parasitisation of Tetrastichus brontispae (Hymenoptera: Eulophidae), a biological control agent of the coconut hispine beetle Brontispa longissima (Coleoptera: Chrysomelidae). BIOCONTROL SCI TECHN., 22(8), 955-968. DOI: 10.1080/09583157.2012.698250

Rashid, P., S. Eapen, S. Devasahayam and T. Jacob (2015). "Effect of temperature on the infectivity of entomopathogenic nematodes against shoot borer (Conogethes punctiferalis Guen.) Infesting ginger (Zingiber officinale Rosc.)." Biol Control, 29(4): 187-193.

Rohde, C., Moino, Jr. A., da Silva, M.A.T., Carvalho, F.D. and C.S. Ferreira (2010). Influence of soil temperature and moisture on the infectivity of entomopathogenic nematodes (Rhabditida: Heterorhabditidae, Steinernematidae) against larvae of Ceratitis capitata (Wiedemann) (Diptera: Tephritidae). Neotropical entomology, 39(4): 608-611.

Sanda, N.B., Muhammad, A., Ali, H. and Y.M. Hou (2018). Entomopathogenic nematode Steinernema carpocapsae surpasses the cellular immune responses of the hispid beetle, Octodonta nipae (Coleoptera: Chrysomelidae). Microbial Pathogenesis, 24: 337-345.

Sanda, N.B., Hou, B., Muhammad, A., Ali, H. and Y. Hou (2019). Exploring the Role of Relish on Antimicrobial Peptide Expressions (AMPs) Upon Nematode-Bacteria Complex Challenge in the Nipa Palm Hispid Beetle, Octodonta nipae Maulik (Coleoptera: Chrysomelidae). Front. Microbiol. 10:2466. doi: 10.3389/fmicb. 2019.02466 .
Shapiro-Ilan, D.I., Han, R. And C. Dolinksi (2012). Entomopathogenic nematode production and application technology. Journal of Nematology, , 44: 206-217.

Sun, J., Yu, P., Zhang, Y. and X. Wang (2003). A new invasive coconut pest in Hainan Province. Entomological Knowledge, 40(3), 286-287. DOI: 10.1111/phen.12081

Susurluk, A. (2008). "Influence of temperature on the vertical movement of the entomopathogenic nematodes Steinernema feltiae (TUR-S3) and Heterorhabditis bacteriophora (TUR-H2), and infectivity of the moving nematodes." Nematology, 10(1): 137-141.

Tang, B. and Y. Hou (2017). Nipa Palm Hispid Beetle Octodonta nipae (Maulik) Biological Invasions and Its Management in China (pp. 257-266): Springer.

Tarasco, E., M. Oreste, X. Li and Q. Liu (2016). "Infectivity of Mediterranean native Entomopathogenic Nematodes (Steinerne matidae and Heterorhabditidae) from natural habitats in relation to temperature." Redia 98(1): 109-114.

Thomas, M.B. and S. Blanford (2003). Thermal biology in insect-parasite interac-tions. Trends in Ecology and Evolution, 18(7): 344-350.

Trdan, S., Vidrih, M., Andjus, L. and Ž. Laznik (2009). Activity of four entomopathogenic nematode species against different developmental stages of Colorado potato beetle, Leptinotarsa decemlineata (Coleoptera, Chrysomelidae). Helminthologia, 46(1).

DOI:10.2478/s11687-009-0003-1.

Vassiliou, V.A., Kazantzis, E. and A. Melifronidou-Pantelidou (2011). First report of the nipa palm hispid Octodonta nipae on queen palms in Cyprus. Phytoparasitica, 39(1), 51-54.

Xin, X., Ma, Z. and W. Qin (2009). Factors affecting host acceptance behavior of Tetrastichus brontispae Ferrière. Chin J Trop Crop, 30, 1120-1123.

Xu, H., Qiang, S., Genovesi, P., Ding, H., Wu, J, Meng. L. and J. Guo (2012). An 
inventory of invasive alien species in China. NeoBiota, 15, 1.

Yadav, A.K. (2012). Efficacy of indigenous entomopathogenic nematodes from Meghalaya, India against the larvae of taro leaf beetle, Aplosonyx chalybaeus (Hope). J Parasit Dis, 36(2), 149-154. DOI 10.1007/s12639-012-0139-7
Yan, X., Han, R., Moens, M., Chen, S. and P. De Clercq (2013). Field evaluation of entomopathogenic nematodes for biological control of striped flea beetle, Phyllotreta striolata (Coleoptera: Chrysomelidae). BioControl, 58(2), 247-256.

NJE Vol. 36: 88-95, 2020

Nigerian Journal of Entomology

Published by the Entomological Soc. of Nig.

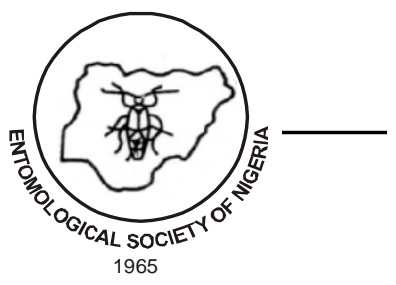

www.esnjournal.com.ng

DOI.10.36108/NJE/0202/63.01.01 